\title{
Industrial and National Aspects of Technical Education
}

$\mathrm{T}$ HE discussion at Aberdeen on September 11 arranged by the Department of Industrial Co-operation of Section F (Economic Science and Statistics) and Section L (Educational Science) of the British Association, on the planning of a national policy of technical education and industrial recruitment, followed very appropriately Mr. H. T. Tizard's presidential address to Section $\mathbf{L}$ and a subsequent discussion in that section on the development of post-primary education during the present century. Mr. Tizard had referred particularly to the way in which the lack of co-operation or understanding between some branches of industry and the universities regarding the character of a university training is liable to lead to engineering graduates, for example, finding themselves in blind alleys or to definite unemployment, as among the biologists. While there can be no two opinions about the folly of a policy of encouraging young men of good ability to spend long years in specialised study, only to find at the end that there is no demand for their services or that the posts offer inadequate prospects, this has been the experience of many science graduates during the past fifteen years. If, however, Mr. Tizard's suggestion that the supply should be deliberately kept short of the demand is not altogether acceptable to industry, the alternative is to attempt some definite planning of technical education both quantitatively and qualitatively in relation to industrial recruitment.

The discussion on this question, while exploring a number of important aspects, was rather disappointing as a definite contribution to the solution of the problem. For this the meagre interest taken in the discussion by industry as a whole may have been responsible, in spite of the valuable contributions of Mr. A. P. M. Fleming and Mr. W. Rintoul. The discussion was opened on the administrative side by a paper by $\mathrm{Mr}$. J. W. Bispham, which surveyed particularly the functions of the technical school and also discussed the effect of raising the school-leaving age, which he considers is inevitable in the near future. The emphasis which was laid on the hardship frequently caused to students, as well as the unwise duplication of equipment, etc., through the sectional treatment of technical education where overlapping or contiguous areas are concerned, indicates the need for national planning of educational facilities. Local rivalries or prejudices are above all out of place in determining educational policy. Equally important is a much closer contact between industrial and educational authorities.

Mr. G. W. Thomson's survey of the position of technical education in Scotland was an important contribution from much the same point of view, but laid considerable stress on the social aspects of the problem. These include the relation of technical education to actual employment, and the dangers of exclusive vocational training. A much larger place for the teaching of English in all technical education was claimed, partly because of its cultural value and as a corrective to the narrow stratification of industrial society, but partly also because of its power to encourage the initiative and originality of thought and expression which industrial conditions often tend to repress. Mr. Thomson also directed attention to the neglect of apprenticeship and to the value of closer correlation between educational authorities and those responsible for the conduct of industry in extending the provisions for part-time study in day classes.

This vigorous plea for the consideration of individual needs in the planning of a policy of technical education was supported by Principal J. Cameron Smail, who however differed as to the place of the teaching of English and cultural values, and deprecated the pushing of selected young people at fourteen or fifteen years of age, urging that a watch should be kept on the education of all young people up to the age of eighteen years. The most serious recent criticism of our system of technical education, that it has been planned too much in accordance with demands from below and not enough in response to requirements from above, was, however, scarcely noted in the discussion, even in the important paper by Mr. A. P. M. Fleming which preceded that by Mr. Thomson. This paper gave a comprehensive account of the methods of recruitment and training used by a large centralised industry, employing 10,000 workers, 3,000 of whom are staff grade, including 800 with technical qualifications. A deliberate attempt has been made in co-operation with educational institutions to effect a planned system of co-ordinating supply and demand, having regard to the influence of the trend of development in engineering plant and apparatus, types and methods of production and markets for new as well as for established engineering products. The scheme attempts to place a premium on ability, and to facilitate promotion of those possessing the requisite qualities from the lowest to the highest positions of responsibility.

In the selection of recruits for training, whether at the usual age of fourteen years for a seven-year apprenticeship system, or of the university trained staff, Mr. Fleming said that reliance is placed on the judgment of the trained staff familiar with this work rather than on vocational or intelligence tests. Attention was directed to the value of a year in the works before proceeding to a university, particularly in avoiding the possibility of a misfit, and also to the value of a cross-connexion between industrial and academic research. Curricula, too, need careful planning if the originality of the investigator is not to be suppressed. On the other hand, post-graduate work and travelling scholarships may well be deferred until some industrial experience has been acquired. Many students are unfit from the start for an industrial career, and in view of the careful practical training now given by some large organisations to their scientific staff, Mr. Fleming suggested that such training invites university recognition by the conferring of a higher degree on men who have pursued such a course in an organisation of accepted standing. The award of research scholarships and the like, enabling the recipient to pursue investigations in laboratories where the facilities are often much greater than in a university, is another way in which co-operation between industry and the universities might be extremely fruitful.

Mr. Fleming's outline not merely of actual achievements but also of some of the possibilities of co-ordination and planning in this field was the most important contribution from the industrial side. Mr. W. Rintoul's paper was limited to a discussion of technical education as applied to the training of 
chemists for industry. Like Mr. Fleming, Mr. Rintoul laid a good deal of stress upon the training which supplements that given at the university. For the analyst, post-graduate training in general research or in chemical engineering, etc., is desirable. For the chemist in charge of plant, a two-year course in research or in chemical engineering might equally be desirable but it is highly important that this postgraduate training should be obtained in a university other than that in which he qualified, so as to widen his outlook as much as possible. On entering industry, a year or so should be given to analytical work.

Stressing the value of the knowledge acquired outside the university in such post-graduate work, Mr. Rintoul emphasised the continual necessity for the works chemist to keep himself in touch with developments by membership of scientific or industrial societies and attendance at their meetings. The suggestion of special leave for selected men for a vefresher course after five years' service or more was akin to suggestions made by Mr. Fleming. Equally for the research chemist, Mr. Rintoul urged that post-graduate training should be carried out in a fresh university on account of the wider technique and experience thus acquired, as well as the greater stimulus given to originality by a change of environment. The training of the chemist for definitely commercial work is probably best completed after entering industry itself.

In most of the papers and in the discussion, full attention was directed to the social aspects involved in planning technical education and particularly the problems raised by mechanisation. Apart, however, from a very demonstrable consciousness that technical education must be regarded as a vital national matter and not a purely local one or the concern of industries by themselves, the discussion made little definite contribution to immediate progress, and the valuable suggestions made from the industrial side scarcely attracted the attention they deserved. None the less, the discussion of this subject at a British Association meeting should at least assist the formulation of a definite and adequate policy in which technical education is treated not as a thing apart, but in relation to those wide issues of juvenile unemployment, industrial efficiency and the raising of the school leaving age from which it cannot be divorced without danger to the community.

\section{The Sanriku (Japan) Earthquake Seawaves of 1933}

$\mathrm{T}$ HE great earthquake that gave rise to these destructive seawaves occurred on March 3, 1933. As soon as the news of the disaster reached Tokyo, several members of the Earthquake Research Institute were sent to the districts principally affected. The chief points that they investigated were the highest levels reached by the tunami or seawaves, the areas of the regions inundated, the damage to houses, etc., and the relations between the effects of the waves and topographical conditions.

Several memoirs have already appeared and an abstract of one of them, by Messrs. Imamura and Kawase (NATURe, 133, 72-73 ; 1934), gives the main facts as regards the height of the waves and the loss of life and property. In March of the present year, or about a year after the earthquake, the reports of the observers have been published. They occupy a whole volume (Supplementary Vol. I) of the Bulletin of the Earthquake Research Institute. To have produced in so short a time a work of such value and interest, accompanied by such wealth of illustration, is a remarkable feat and one for which seismologists can scarcely be too grateful. The volume contains 521 pages and 251 plates. The first half consists of sixteen memoirs, thirteen of which are written in English and the rest in Japanese with abstracts in English. The second half contains the reports of the observers, which, except for a brief abstract of two pages and the titles of the plates, are written entirely in Japanese.

Besides these investigations, experiments are being made in the Institute laboratory in which, by means of models, the natural conditions are imitated as far as possible. They are still unfinished, but the final results, which will be published shortly by the Institute, can scarcely fail to throw light on the nature of earthquake seawaves.

The tide-tables show that the sea at the time of the earthquake was practically at mean sea-level. The heights reached by the waves were determined from the marks left by them on houses, trees and cliffs. As a rule, the heights reached in 1933 were slightly less than those in 1896 , but some of them were considerable, the greatest being $94 \mathrm{ft}$. at Sirahama in Ryôri.

The propagation of the seawaves is studied by Prof. N. Miyabe (pp. 112-126). They were recorded by mareographs at eighteen stations in Japan, only one of which lies on the Japan Sea side. Unfortunately, the times at which the first waves arrived cannot always be determined with precision, and there may be errors of as much as five minutes in the estimates. Taking their probable values and using the formula $v=\sqrt{ }(g h)$, Prof. Miyabe has drawn circles with the stations as centres, and radii equal to the distances the waves would travel in the intervals between the time of the earthquake and the times of arrival at the respective stations. These circles do not intersect in a point, but envelop one side of an area about $600 \mathrm{~km}$. in length from north to south. Thus, it is possible that the displacement that gave rise to the seawaves may have been several hundred miles in length. The seawaves were also recorded by mareographs at Honolulu, San Francisco and Santa Monica (Cal.). The mareograms at Manila and Wellington (N.Z.) show no trace of the waves, perhaps on account of the disturbing effect of intermediate islands. Nor do those at Sydney and Melbourne record them with certainty. On the other hand, they are shown with considerable amplitude at Iquique in Chile, though that station is nearly 9,000 miles from the origin.

Mr. K. Musya describes in great detail the luminous phenomena observed with the seawaves (pp. 87-111). $\mathrm{He}$ classifies them according to the following types: the crest of the waves emitted dim continuous light (for Prof. Terada's explanation of this light, see Nature, 133, 73; 1934); the surface of the sea glittered all over; the waves on the shore-line gave out bluish light; when the sea-water receded before the arrival of the great waves, the exposed sea-bed gave out blue light; a luminescent body like a meteor was seen; well-defined round luminous bodies were seen in an incoming wave; a round-shaped luminous body appeared above the sea; and bright light radiated from the sea.
C. Davison. 